\title{
Opposing Roles of Nucleus Accumbens Core and Shell Dopamine in the Modulation of Limbic Information Processing
}

\author{
Rutsuko Ito and Anja Hayen \\ Department of Experimental Psychology, University of Oxford, Oxford OX1 3UD, United Kingdom
}

The dopaminergic innervation of the nucleus accumbens (NAc) is implicated in the selection and integration of motivationally relevant corticolimbic information that governs behavioral output. However, it is unknown whether the dopaminergic innervations of two anatomically distinct subregions of the NAc, core and shell, have differential roles in this gating process, and whether dopaminergic mechanisms are important in regulating the balance of limbic control over appetitive behavior at the point of learning. Having previously shown that repeated systemic pretreatment with amphetamine disrupts the regulation of competing limbic control over appetitive behavior in mice, we hereby examined the effects of repeated pretraining intra-NAc shell or core microinfusions of D-amphetamine, general dopamine (DA) receptor antagonist cis-flupenthixol, or vehicle solution (saline) upon a simultaneously acquired conditioned cue and place preference task in rats. Repeated infusions of amphetamine into the NAc shell and core had opposite effects on the acquisition of conditioned place preference by significantly enhancing and attenuating, respectively, hippocampal-dependent place conditioning. In contrast, direct infusions of flupenthixol into the NAc shell attenuated place conditioning, while NAc core flupenthixol infusions not only attenuated cue conditioning, but also enhanced conditioned place preference. These findings implicate the NAc shell DA as being necessary for enabling hippocampal-dependent spatial information to gain control over appetitive learning, and the NAc core DA as being important for allowing basolateral amygdala-dependent information to gain control over appetitive learning. It is further proposed that NAc core DA may be critical in regulating limbic information flow through the NAc shell.

\section{Introduction}

The nucleus accumbens (NAc) is popularly known to act as a limbic-motor interface, where learned associations of motivational significance are converted into goal-directed behavior (Mogenson et al., 1980). Neurophysiological and neuroanatomical studies have revealed potential neural mechanisms by which the NAc and its dopaminergic innervation may select and integrate the limbic and cortical inputs that acquire control over behavior (Pennartz et al., 1994; Floresco et al., 2001; French and Totterdell, 2002; Goto and Grace, 2005; Gruber et al., 2009). The full characterization of these mechanisms is important, given that the loss of control over this gating process may give rise to the manifestation of aberrant behaviors in diseases such as addiction and schizophrenia (Grace, 2000; Ito and Canseliet, 2010). We have previously shown, for instance, that repeated exposure to amphetamine, known to induce long-term changes in mesocorticolimbic dopamine (DA) neurotransmission (Paulson and Robinson, 1995;

\footnotetext{
Received Dec. 17, 2010; revised Feb. 14, 2011; accepted Feb. 23, 2011

Author contributions: R.I. designed research; R.I. and A.H. performed research; R.I. analyzed data; R.I. and A.H. wrote the paper.

This work was supported by Wellcome Trust Grant WT078197 awarded to R.I. We are grateful to Melissa Canseliet and Greg Daubney for their assistance in surgery and histology, and to Drs. Andy Lee, David Sanderson, and Stephen McHugh for advice on statistical analyses.

Correspondence should be addressed to Dr. Rutsuko Ito, Department of Experimental Psychology, University of Oxford, South Parks Road, 0xford 0X1 3UD, UK. E-mail: rutsuko.ito@psy.ox.ac.uk.

DOI:10.1523/JNEUROSCI.6588-10.2011

Copyright $\odot 2011$ the authors $\quad 0270-6474 / 11 / 316001-07 \$ 15.00 / 0$
}

Pierce and Kalivas, 1995, 1997), affects the balance of limbic information processing, preferentially enhancing hippocampal control, while suppressing basolateral amygdala (BLA) control over appetitive behavior (Ito and Canseliet, 2010).

The NAc itself is differentiated into at least two anatomically and functionally distinct regions, the core and the shell, with different but overlapping patterns of limbic connectivity (Zahm, 1999, 2000; Voorn et al., 2004). Thus, while the NAc shell receives converging limbic inputs from the BLA and ventral subiculum, the major output region of the hippocampus (HPC), the NAc core receives inputs from the BLA and parahippocampal regions (Groenewegen et al., 1999; French and Totterdell, 2003; Voorn et al., 2004). Furthermore, accumulating evidence implicates the NAc shell in the control of reward- or drug-seeking behavior by spatial/contextual information, and the NAc core in the control over such behaviors by discrete cues (Bossert et al., 2007; Ito et al., 2008; Chaudhri et al., 2010); differential processes that have previously been shown to depend on the integrity of the HPC and BLA, respectively (Ito et al., 2006; Ito and Canseliet, 2010). There is also evidence of region-specific DA receptor modulation $\left(D_{1}\right)$ of discrete cue and context-induced reinstatement of heroin-seeking behavior (Bossert et al., 2007). However, it is unclear whether dopaminergic mechanisms in the NAc core and shell make differential contributions to the modulation of hippocampal- and amygdaladependent processes at the point of learning.

The goal of the present study was to test the hypothesis that repeated pretraining DA manipulations within the NAc core and shell 
have a differential impact upon the regulation of limbic control over appetitive learning. Using a novel task in which spatial (place) cues and a discrete cue were in direct competition with one another for associative strength, and the rate of acquisition was monitored by daily conditioned preference tests, we examined the effects of repeatedly augmenting (D-amphetamine) and blocking (cis-flupenthixol) DA neurotransmission in the NAc core and shell upon reward-related spatial and discrete cue learning. We present findings of a double dissociation in the role of NAc shell and core DA in regulating the balance of limbic control over appetitive learning, revealing a special role for NAc core DA in regulating limbic throughput in the NAc shell.

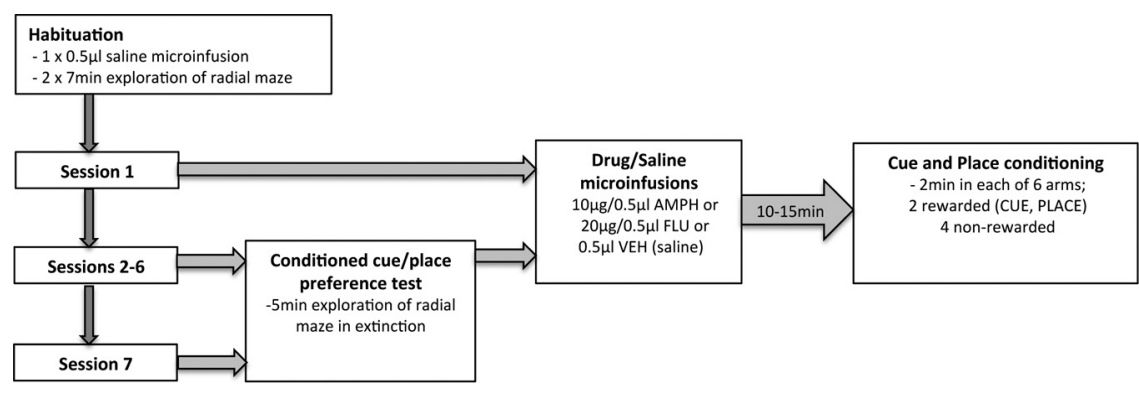

Figure 1. Summary of the sequence of events in the concurrent cue and place conditioning paradigm. Following the habituation day, animals received six daily conditioning sessions, each preceded by drug (amphetamine or flupenthixol) or saline infusions in a separate room. In addition, a conditioned cue/place preference test $(5 \mathrm{~min}$ ) was conducted in a drug-free state on sessions $2-7$ (before the drug infusions) to monitor the rates of acquisition of cue and place conditioning.

\section{Materials and Methods}

\section{Subjects}

Subjects were 57 male Lister hooded rats (Charles River Laboratories) weighing $\sim 330-400 \mathrm{~g}$ at the time of surgery. They were housed in groups of two or three in a room held at a constant temperature of $21^{\circ} \mathrm{C}$, under a $12 \mathrm{~h}$ light/dark cycle (lights on at 7:00 A.M.). Water was available ad libitum, but before the start of behavioral testing, food (laboratory chow, Purina) was restricted to $20 \mathrm{~g}$ of lab chow/d, sufficient to maintain preoperative/treatment body weight and growth. All experiments were conducted during the light phase and in accordance with the United Kingdom 1986 Animals (Scientific Procedures) Act Project License No. 30/2561.

\section{Surgery}

All rats were anesthetized with isoflurane (Abbott Laboratories) and placed in a stereotaxic frame (Kopf) with the incisor bar set at $-3.3 \mathrm{~mm}$ below the interaural line. A 26 gauge bilateral guide cannula (Plastics One) was then implanted, targeting the NAc core or the NAc shell using the following coordinates (in $\mathrm{mm}$ from bregma): $\mathrm{AP}=+1.2 ; \mathrm{L}= \pm 1.5$; $\mathrm{V}$ (from skull surface $)=-6.0$ and $\mathrm{AP}=+1.2 ; \mathrm{L}= \pm 1.0 ; \mathrm{V}=-5.8$, respectively. The guide cannula was anchored to the skull with dental cement (Kemdent Works) and skull screws. Stainless steel stylets (Plastics One) were placed in the guide cannulae to maintain their patency throughout the training period. Following surgery, rats were allowed a recovery period of at least $7 \mathrm{~d}$ before behavioral testing with food available ad libitum.

\section{Conditioned cue and place preference task}

Radial arm maze apparatus. Behavioral testing took place in an automated six-arm radial maze (Med Associates) placed on a rotatable table elevated $80 \mathrm{~cm}$ from the floor. The maze consisted of six enclosed arms $[45.7 \mathrm{~cm}(\mathrm{~L}) \times 16.5 \mathrm{~cm}(\mathrm{H}) \times 9.0 \mathrm{~cm}(\mathrm{~W})]$ emanating from a central hexagonal hub compartment with six automatic stainless steel guillotine doors allowing access to the arms. Arms were enclosed by Plexiglas walls and a removable Plexiglas lid and contained a grid floor. At the end of each arm was a receding well consisting of a stainless steel tray that could be connected up to a syringe pump for the delivery of sucrose solution (Med Associates). Each arm was also equipped with two sets of infrared beams located 2 and $3 \mathrm{~cm}$ away from the entrance of the arm to monitor an animal's entry into and exit out of the arm.

The maze itself was placed in a testing room with various extramaze cues (stools, set of drawers, curtain), which remained in the same positions throughout the experiment. The maze was wiped down with ethanol solution after each session to eliminate odor traces and the maze was randomly rotated left or right by varying degrees $\left(60^{\circ}, 120^{\circ}\right.$, or $\left.180^{\circ}\right)$ at the end of the testing day to minimize conditioning to intramaze cues.

General microinfusion procedure. All rats were habituated to the infusion room and to gentle hand restraint for $5 \mathrm{~min}$ on each of the three days before the start of drug infusion. In addition, just before the first habituation session, each animal underwent a vehicle infusion $(0.5 \mu \mathrm{l}$ of saline) to minimize the mechanical effects of subsequent infusions, as well as habituate the animals to the infusion procedure. For subsequent drug

infusions, rats were held by hand while bilateral 33 gauge microinjectors projecting beyond the tip of the guide cannula by $1.5 \mathrm{~mm}$ were placed in the guide cannula. Drug injections were conducted over 1 min using an infusion pump (Harvard Apparatus) mounted with $5 \mu$ l Hamilton syringes, and the injector was left in place for a further $1 \mathrm{~min}$ to ensure diffusion of the drug away from the tip before removal. All drug infusions were performed in a room separate from the animals' housing and behavioral testing environment, following which the animals were transported to the testing room. Behavioral testing began 10-15 min after the end of the infusion.

\section{Experimental procedure (see Fig. 1)}

Habituation. Following a single vehicle infusion, all rats were given two 7 min habituation periods (one in the morning, one in the afternoon) on the day before the first drug infusion and conditioning session. They were initially placed in the central hub of the apparatus. After an adaptation time of $1 \mathrm{~min}$ in the hub, all six guillotine doors were opened and the rats were free to explore the whole maze for a further $6 \mathrm{~min}$ (with the floor insert cue placed in one of the arms). Two short sessions of habituation periods were given (rather than one 14 min session), as this enabled better acclimatization to the noise of the automated guillotine door opening and closing.

Drug infusions (sessions 1-6). Rats were assigned to one of three infusion groups: amphetamine $(n=19)$, cis-flupenthixol $(n=21)$, or saline vehicle (VEH; $n=17$ ). For each of the six sessions, rats in the amphetamine infusion group received a bilateral infusion of $10 \mu \mathrm{g} / 0.5 \mu \mathrm{l} \mathrm{am}-$ phetamine (Sigma-Aldrich) dissolved in sterile $0.9 \%$ saline before the conditioning session. Similarly, rats in the flupenthixol group received a bilateral infusion of $20 \mu \mathrm{g} / 0.5 \mu \mathrm{l}$ cis-flupenthixol (Sigma-Aldrich) dissolved in sterile $0.9 \%$ saline before each conditioning session. Animals in the saline vehicle group received a bilateral infusion of $0.5 \mu \mathrm{l}$ of $0.9 \%$ sterile saline solution. All drug infusions were spaced at least $24 \mathrm{~h}$ apart. Drug doses and infusion intervals were selected based both on our own pilot experiments and a previous study demonstrating selective behavioral effects of manipulating the NAc subregions (Wyvell and Berridge, 2000).

Concurrent cue and place conditioning (sessions 1-6). Following each drug infusion, rats were brought into the behavioral testing room to start the conditioning session. Rats were initially placed in the central hub compartment of the radial maze for $30 \mathrm{~s}$. They were then confined in each of the six arms for $2 \mathrm{~min}$, with the order of presentation of the arms randomized across sessions for each animal. The rat received five aliquots of $0.3 \mathrm{ml}$ of $20 \%$ sucrose solution within the 2 min confinement period in two arms: (1) the "cue" arm, which contained a continuous black rubber floor insert (cue conditioning) that was moved between different arms in a pseudorandom fashion (all arms except the place arm) across each session, and (2) the "place" arm, which was fixed in a particular spatial location (place conditioning). In summary, rats received sucrose reward in the arm with the floor insert (cue arm) regardless of its spatial location, and in the arm that happened to occupy a fixed spatial location (place arm) in that particular session. The maze was rotated at the end of each day to minimize conditioning to the arms themselves, or other intramaze 

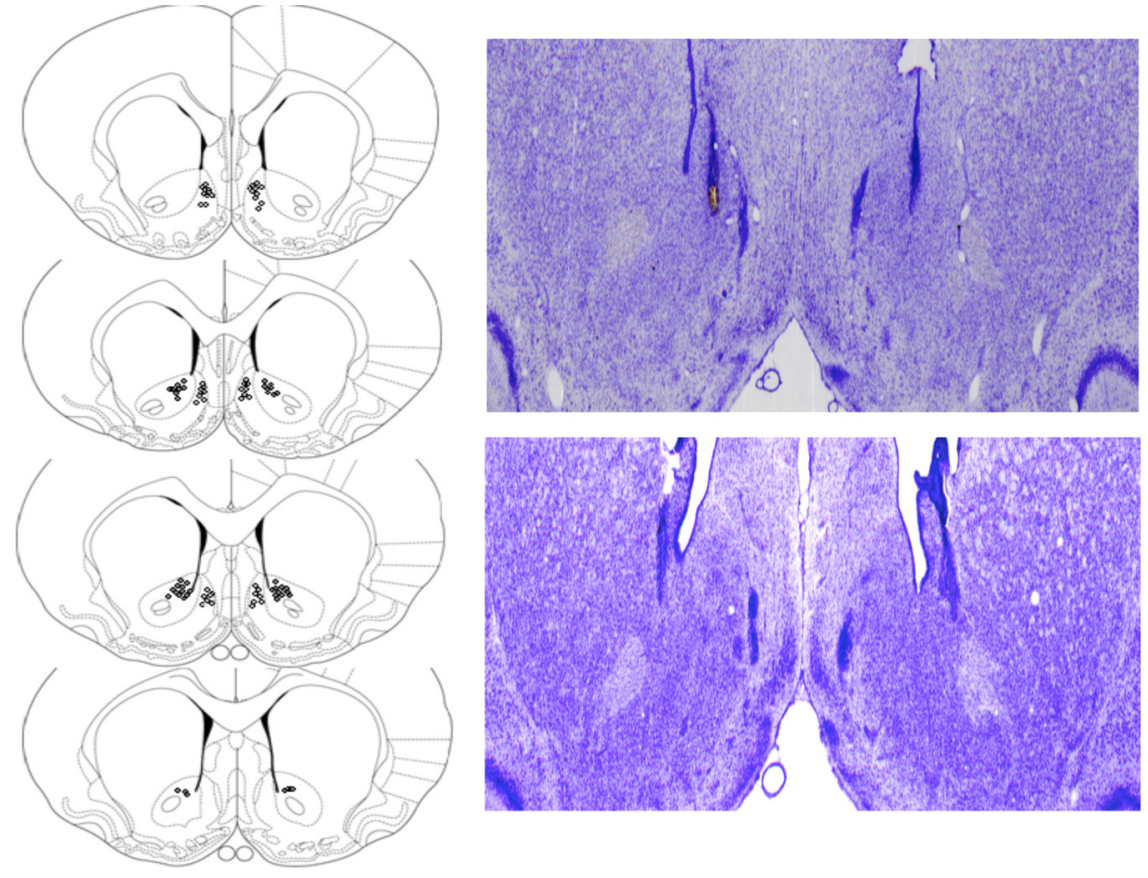

Figure 2. Schematic (left) and photomicrographic representation (right) of the locations of injector tips in the NAc core and shell, based on the stereotaxic atlas of the rat brain of Paxinos and Watson (1997).

cues. The rats did not receive any reward in the remaining four arms [nonrewarded (NR)].

Conditioned cue and place preference test (sessions 2-7). On the day after each conditioning session, rats were given a conditioned cue and place preference test in a drug-free state (before the next drug infusion and conditioning session) to assess the degree of conditioning to the cue and place. They were given $5 \mathrm{~min}$ to explore the entire apparatus, in the absence of any reward, and the time spent in each arm was recorded. A total of six preference tests were conducted for each animal. The last test (sixth) in session 7 was not followed by any drug infusion or conditioning session.

\section{Histological procedure}

All rats were anesthetized with sodium pentobarbitone $(1.5 \mathrm{ml} / \mathrm{animal}$, $200 \mathrm{mg} / \mathrm{ml}$ Euthatal, Rhone Merieux) and perfused intracardially via the ascending aorta with $0.01 \mathrm{M}$ PBS, followed by $10 \%$ formalin saline. Brains were then removed, stored in $10 \%$ formalin, and transferred to a $30 \%$ sucrose cryoprotectant solution before sectioning. Coronal sections (50 $\mu \mathrm{m}$ ) of the brain were cut using a freezing microtome and were then stained with cresyl violet, to be viewed under the microscope for the verification of cannula placements.

\section{Data analysis}

All data were analyzed using the SPSS statistical package version 19.0. Data generated for each conditioned preference test session ( $5 \mathrm{~min}$ ) consisted of the absolute time spent in each of the six arms of the radial maze as well as the time spent in the hub. A four-way repeated-measures analysis of covariance (ANCOVA) was conducted with cannula placement (region; NAc core or NAc shell) and drug treatment (amphetamine, flupenthixol, and saline vehicle) as between-subject factors, with test sessions (six sessions) and arm [cue, place, and nonrewarded (mean of time spent in the four nonrewarded arms)] as within-subjects factors. In addition, due to the fact that the degree of exploration during the preference tests was highly variable between rats (and could therefore lead to marked differences in the absolute times spent in arms), the mean of the total time spent exploring the six arms ( 5 min session time - time spent in hub) across six tests was calculated for each rat, and applied as a covariate. A significant three-way interaction was further explored using three-way ANCOVAs in which the time spent in the cue, place, and NR arm (mean of time spent in four NR arms) was analyzed separately. Where further significant interactions were found, simple main effects were calcu- lated by one-way ANCOVAs. Subsequent post hoc comparisons for simple main effects were performed with a Sidak correction. Furthermore, based on a priori predictions that the acquisition of conditioned place preference is an incremental process, and will only begin to be established after 5-6 conditioning sessions in the control (saline) groups, we conducted a separate fully factorial ANCOVA on the performance of all the animals in test session 6 to assess the establishment of conditioned cue and place preference.

\section{Results \\ Cannula placement}

A schematic diagram and representative photomicrographs of the placement of injector tips within the NAc core and shell subregions are shown in Figure 2, based on the stereotaxic atlas of the rat brain of Paxinos and Watson (1997). Data from nine animals were excluded from statistical analyses due to incorrect placements $(n=5)$, loss of the cannula during the course of training $(n=1)$, or a failure to consume the reward during the conditioning sessions $(n=3)$. The final group numbers were as follows: NAc shell saline, $n=7$; NAc core saline, $n=9$; NAc shell amphetamine, $n=7$; NAc core amphetamine, $n=7$; NAc shell flupenthixol, $n=11$; NAc core flupenthixol, $n=7$.

\section{Acquisition of conditioned cue and place preference}

An overall four-way ANCOVA conducted on the time spent in the cue, place, and NR arms across the six conditioning tests revealed significant main effects of arm $\left(F_{(2,82)}=4.17, p<0.05\right)$, session $\left(F_{(5,205)}=2.89, p<0.05\right)$, and drug treatment $\left(F_{(2,41)}=5.90\right.$, $p<0.01)$ as well as a significant arm $\times$ drug treatment interaction $\left(F_{(4,82)}=2.81, p<0.05\right)$, session $\times$ drug treatment interaction $\left(F_{(10,205)}=2.24, p<0.05\right)$, and arm $\times$ drug treatment $\times$ region interaction $\left(F_{(4,82)}=8.21, p<0.0001\right)$, indicating that there were significant differences in the effect of drug infusions into the NAc core or shell in different conditioning arms.

\section{Effects of repeated intra-NAc core and shell amphetamine and flupenthixol on cue conditioning}

The acquisition of conditioned cue preference in rats given pretraining intra-NAc core or shell amphetamine, saline, or flupenthixol infusions is shown in Figure 3. To examine the effect of amphetamine and flupenthixol infusions into the NAc core or shell on conditioned cue preference, a three-way ANCOVA was conducted on the time spent in the cue arm across the six test sessions with drug treatment (amphetamine, flupenthixol, and saline vehicle) and region (NAc core, shell) as the betweensubject factors. The analysis revealed significant main effects of drug treatment $\left(F_{(2,41)}=4.92, p<0.01\right)$ and session $\left(F_{(5,205)}=\right.$ 4.84, $p<0.0001)$ and a significant region $\times$ drug treatment interaction $\left(F_{(2,41)}=4.88, p<0.01\right)$, after controlling for the effect of individual differences in the degree of exploration during the tests. Subsequent simple main effects analyses revealed a significant main effect of drug treatment in the NAc core $\left(F_{(2,41)}=\right.$ $7.44, p<0.01)$, but not the NAc shell $\left(F_{(2,41)}=1.347, p=0.27\right)$, which was due to the overall level of time spent in the cue arm across six sessions being significantly reduced in the group in- 


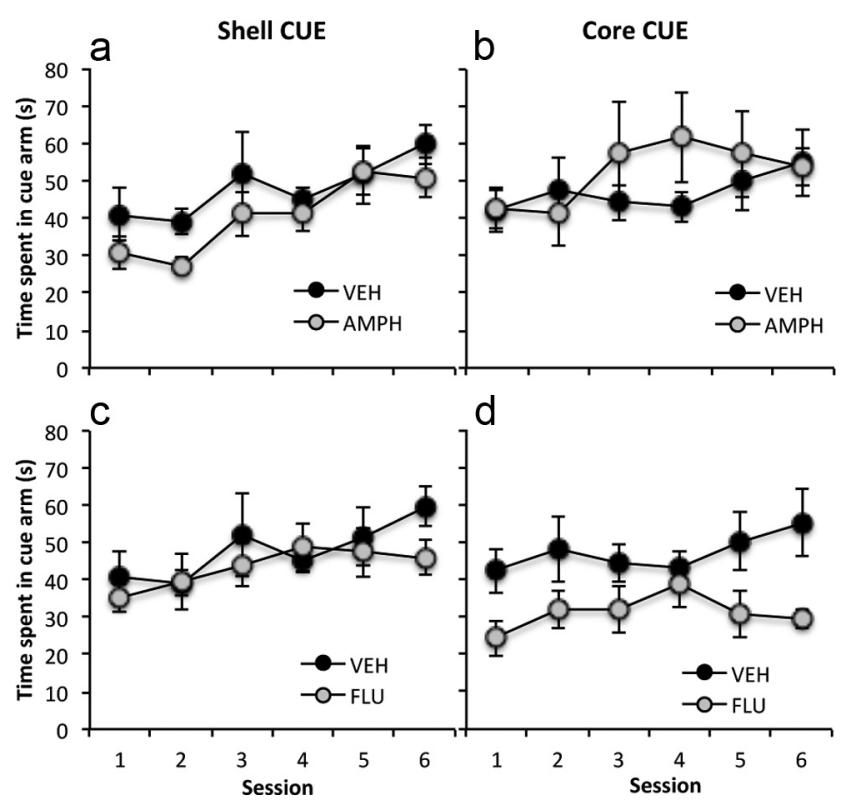

Figure 3. The mean time spent in the cue arm ( \pm SEM) in the six conditioned cue and place preference tests ( $5 \mathrm{~min}$ ) for NAc shell saline control group (VEH, $n=7$ ) and shell amphetamine treatment group (AMPH, $n=7)(\boldsymbol{a})$, NAc core saline control group (VEH, $n=9$ ) and core amphetamine treatment group (AMPH, $n=7)(\boldsymbol{b})$, NAc shell saline control group (VEH) and shell cis-flupenthixol treatment group (FLU, $n=11)(c)$, and NAc core saline control group (VEH) and core cis-flupenthixol treatment group (FLU, $n=7)(\boldsymbol{d})$.

fused with flupenthixol in the NAc core, compared with the saline-infused group $(p<0.02)$.

\section{Effects of repeated intra-NAc core and shell amphetamine and flupenthixol on place conditioning}

The acquisition of conditioned place preference in rats given pretraining intra-NAc core or shell amphetamine or saline infusions is shown in Figure 4. A three-way ANCOVA conducted on the time spent in the place arm across the six tests for the intra-core or -shell amphetamine, flupenthixol, and saline groups revealed a significant region $\times$ drug treatment interaction $\left(F_{(2,41)}=12.53\right.$, $p<0.0001)$ and a significant test session $\times$ drug treatment interaction $\left(F_{(10,205)}=2.83, p<0.01\right)$, but no significant main effect of session $\left(F_{(5,205)}=1.28, p 0.27\right)$, drug $\left(F_{(2,41)}=1.53, p=0.23\right)$, or region $\left(F_{(1,41)}=0.004, p=0.95\right)$ after controlling for the effect of individual differences in the degree of exploration during the tests.

Subsequent simple main effects analyses showed a significant main effect of drug treatment in both the NAc shell $\left(F_{(2,41)}=11.08\right.$, $p<0.0001)$ and NAc core $\left(F_{(2,41)}=3.69, p<0.05\right)$, and a significant main effect of region with both amphetamine $\left(F_{(1,41)}=11.59, p<\right.$ $0.001)$ and flupenthixol $\left(F_{(1,41)}=14.47, p<0.0001\right)$ infusions, but not saline infusions $\left(F_{(1,41)}=0.005, p=0.94\right)$. Sidak-corrected post hoc comparisons revealed that infusions of amphetamine into the NAc shell significantly increased the overall time spent in the place arm compared to that in the saline-infused animals $(p<0.02)$, while infusions of flupenthixol into the NAc shell significantly decreased the overall time spent in the place arm compared to that in the saline-infused animals $(p<0.05)$. In contrast, infusions of flupenthixol into the NAc core had the opposite effect of significantly increasing the overall time spent in the place arm compared to that in the saline-infused animals $(p<0.05)$. Amphetamine infusions into the NAc core did not significantly alter the overall time spent in the place arm compared to that in the saline-infused group $(p=0.80)$. However, visual inspection of

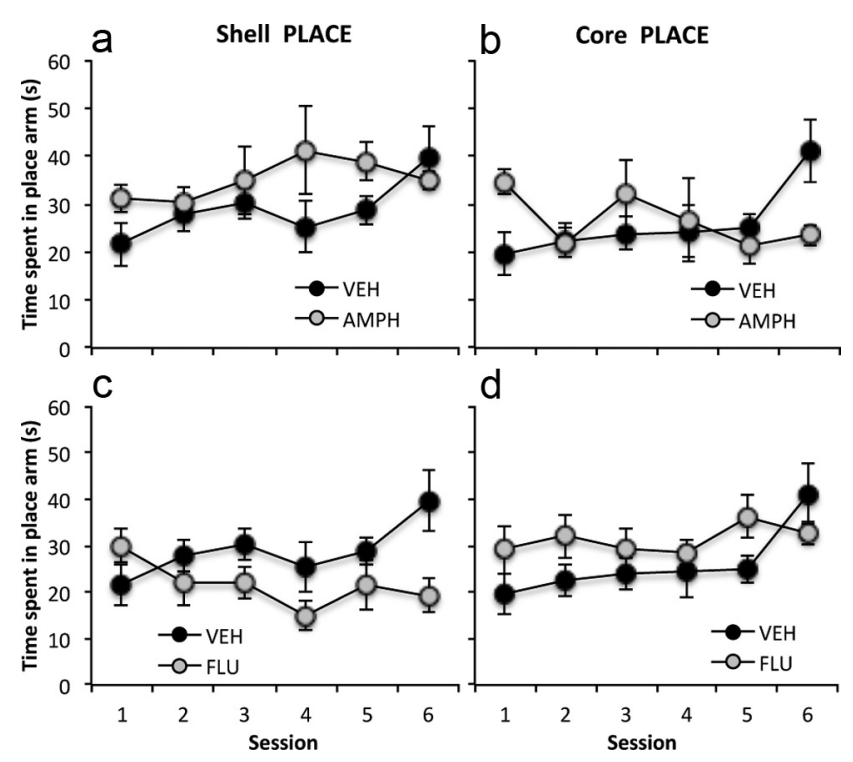

Figure 4. The mean time spent in the place arm ( \pm SEM) in the six conditioned cue and place preference tests ( $5 \mathrm{~min}$ ) for NAc shell saline control group (VEH) and shell amphetamine treatment group (AMPH) (a), NAc core saline control group (VEH) and core amphetamine treatment group (AMPH) (b), NAc shell saline control group (VEH) and shell cis-flupenthixol treatment group (FLU) (c), and NAc core saline control group (VEH) and core cisflupenthixol treatment group (FLU) (d).

Figure $4 b$ suggests that the absence of any significant difference in the overall time spent in the place arm between the NAc core amphetamine- and saline-infused groups could be due to the fact that the time spent in the place arm by the NAc core amphetamine group only appeared to differ from the performance of the NAc core saline group in test sessions 1 and 6. A separate post hoc ANCOVA comparing the performance of the core amphetamine group with that of the core vehicle group revealed a significant drug treatment $\times$ test session interaction $\left(F_{(5,65)}=3.73, p<\right.$ 0.01 ), which was due to the level of conditioned place preference of the core amphetamine group being higher than that of the saline group in test $1(p<0.05)$, but lower than that of the saline-infused group in test $6(p<0.05)$.

\section{Effects of repeated intra-NAc core and shell amphetamine} and flupenthixol on the time spent in the nonrewarded arms A three-way ANCOVA conducted on the time spent in the nonrewarded arms across the six tests did not yield any significant main effects of session $\left(F_{(5,205)}=0.55, p=0.74\right)$, region $\left(F_{(1,41)}=\right.$ $0.50, p=0.48)$, or drug treatment $\left(F_{(2,41)}=2.48, p=0.10\right)$, or drug treatment $\times$ region interaction $\left(F_{(2,41)}=0.69, p=0.51\right)$.

\section{Conditioned cue and place preference in test 6}

A separate ANCOVA was conducted on the performance of the animals in test session 6 (Fig. 5) to examine the cumulative outcome of cue and spatial conditioning. The analysis revealed a significant arm $\times$ drug treatment $\times$ region interaction $\left(F_{(4,82)}=\right.$ $3.12, p<0.02)$ and a significant main effect of drug treatment $\left(F_{(2,41)}=6.25, p<0.01\right)$ and $\operatorname{arm}\left(F_{(2,40)}=41.42, p<0.0001\right)$ after controlling for the effect of individual differences in the degree of exploration during the test. Subsequent simple main effects analyses revealed a significant effect of drug treatment within the NAc core $\left(F_{(2,41)}=4.57, p<0.02\right)$ and NAc shell $\left(F_{(2,41)}=3.92, p<0.03\right)$, and a significant main effect of arm in all groups (NAc shell: saline, $F_{(2,40)}=7.75, p<0.0001$; amphetamine, $F_{(2,40)}=9.32, p<0.0001$; flupenthixol, $F_{(2,40)}=10.78$, 


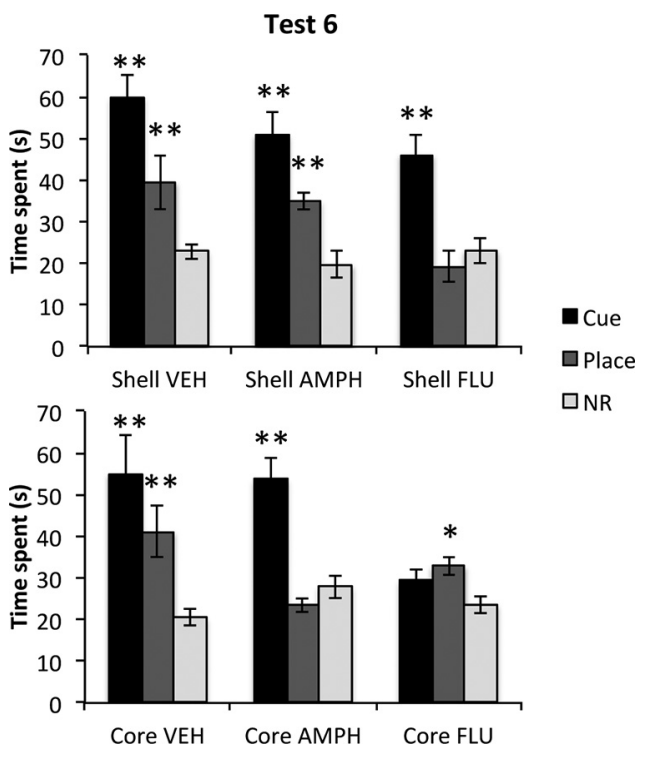

Figure 5. Conditioned cue and place preference test 6 ( $5 \mathrm{~min}$ ) for saline-infused controls (Core-VEH, Shell-VEH), intra-NAc core or shell amphetamine treatment groups (Core-AMPH, Shell-AMPH), and cis-flupenthixol treatment groups (Core-FLU, Shell-FLU), expressed as the mean \pm SEM time spent in the cue arm, place arm, and nonrewarded (NR) arms. ${ }^{*} p<0.05$, ${ }^{* *} p<0.01$ significant difference between the time spent in the cue/place arm and NR arms.

$p<0.0001$; NAc core: saline, $F_{(2,40)}=18.56, p<0.0001$; amphetamine, $F_{(2,40)}=8.05, p<0.0001$; flupenthixol, $F_{(2,40)}=3.30, p<$ $0.05)$. Sidak-corrected post hoc comparisons revealed that all groups showed significant preference for the cue arm over the NR arm except for the NAc core flupenthixol-infused group $(p=$ $0.13)$. Significant preference for the place arm over the NR arm was observed in all groups except for the NAc shell flupenthixol $(p=0.88)$ and NAc core amphetamine $(p=0.62)$ groups.

In summary, repeated flupenthixol infusions into the NAc core, but not the NAc shell, caused significantly attenuated levels of conditioned cue preference. In contrast, repeated amphetamine infusions into the NAc core and shell had no effect on cue conditioning. Repeated intra-NAc shell amphetamine infusions significantly and selectively enhanced conditioned place preference, compared to the saline-infused group. In contrast, repeated intra-NAc core amphetamine infusions initially enhanced place conditioning, but place preference was attenuated with further conditioning sessions.

\section{Discussion}

The main findings of the present experiment are that repeated pretraining amphetamine-induced augmentation of DA in the NAc shell selectively enhances spatial control over appetitive learning, while an increase in DA in the NAc core has the opposite effect of attenuating spatial control over learning. In contrast, repeated blockade of DA neurotransmission in the NAc shell selectively attenuates spatial control over appetitive conditioning, while the same manipulation in the NAc core has the effect of not only attenuating cue conditioning, but also of enhancing spatial conditioning. These findings demonstrate doubly dissociable roles of the dopaminergic innervation of the NAc shell and core in regulating the balance of limbic control over appetitive learning, and also provide further insights into the functional relationship between the NAc core and shell DA, possibly suggesting that NAc core DA may have a "regulatory" role over NAc shell DA function.

\section{Roles of NAc shell and core DA on limbic control over appetitive conditioning}

The pattern of acquisition of conditioned cue and place preference in the saline-infused control rats was consistent with that seen in our previous study, namely, that discrete cues have dominant control over conditioned preference behavior early in training, with conditioned place preference only emerging after six reward-place pairings (Ito and Canseliet, 2010). We have previously demonstrated that these two forms of conditioning (cue vs place) are mediated by different neural systems, with the BLA being critical for discrete cue control over behavior, and the HPC being critical for "place" or spatial control over behavior (Ito et al., 2008; Ito and Canseliet, 2010). Repeated pretraining infusions of amphetamine into the NAc shell caused a marked shift in the balance of limbic control over conditioned preference behavior in favor of spatial (HPC-dependent) control, even after one conditioning session. The present finding, together with previous evidence that repeated systemic administration of amphetamine augments spatial conditioning while attenuating cue conditioning (Ito and Canseliet, 2010), suggests that a hyperdopaminergic state in the NAc shell at the time of new associative learning can lead to enhanced processing of HPC information. Increased DA tone in the NAc shell may result in the attribution of excessive salience to HPC inputs, and thereby potentiate the conditioned reinforcing properties of spatial cues, in accord with the extensive data implicating mesolimbic DA in the attribution of incentive value to cues associated with reward (Carr and White, 1983; Taylor and Robbins, 1984; Robinson and Berridge, 1993; Taylor and Horger, 1999; Wyvell and Berridge, 2000; Robinson and Berridge, 2001). Thus, the present study highlights the key role of a dopaminergic mechanism in the NAc shell, which most likely involves the coactivation of $\mathrm{D}_{1}$ receptors and NMDA receptors (Floresco et al., 2001, Goto and Grace, 2005), in preferentially enabling HPC inputs to govern rates of appetitive learning under normal circumstances.

The attenuation of conditioned place preference by infusions of cis-flupenthixol into the NAc shell, coupled with the attenuation of conditioned cue preference by intra-NAc core flupenthixol infusions not only confirm the importance of DA mechanisms in the effects seen in this study with amphetamine infusions, but is also consistent with a growing number of studies showing dissociable functions of the NAc core and shell in discrete cue and contextual control over drug- and reward-seeking behavior. We have previously shown that the NAc shell and the NAc shell-HPC pathway are critical for the acquisition of reward-related spatial context conditioning, while the integrity of the NAc core and its dopaminergic innervation is critical for discrete cue conditioning, and mediating conditioned influences of discrete cues associated with cocaine (Ito et al., 2000, 2008). Similarly, the NAc core and its $D_{1}$ receptors have been shown to be necessary for discrete cue-induced reinstatement of ethanol-, cocaine-, and heroin-seeking behavior, while the NAc shell and its $D_{1}$ family of receptors has been shown to be critical for the context-induced reinstatement of drug-seeking behavior (Fuchs et al., 2004; Bossert et al., 2007; Chaudhri et al., 2010). Thus, our data strongly implicate the importance of NAc shell DA in the processing of spatial cue-reward association, and the NAc core DA in the processing of discrete cue-reward association.

The present study is based upon the premise that NAc DA plays a crucial role in regulating the competition between BLA and HPC inputs over appetitive behavior. There is substantial evidence suggesting that BLA- and HPC-dependent learning systems interact competitively. Thus, lesions of the HPC can facilitate amygdala-dependent learning (McDonald and White, 1993; 
Ito et al., 2006) and conversely, amygdala lesions can facilitate HPC-dependent learning (Ito et al., 2006). Furthermore, electrophysiological studies have found that BLA and HPC inputs converge upon the same neurons in the NAc (Pennartz et al., 1994), and that DA release facilitated by stimulation of HPC inputs can suppress BLA-evoked activity in the same neurons (Floresco et al., 2001). However, there is also evidence suggesting that the interaction between the BLA and HPC can be modulatory, most likely through direct anatomical connections between the two structures (Pitkänen et al., 2000). Thus, HPC-dependent memory in a water maze task is enhanced by posttraining intraamygdala amphetamine infusions, suggesting that the amygdala can exert a modulatory influence upon HPC processes (Packard et al., 1994; Packard and Teather, 1998). While it is unclear whether such posttraining modulation is mediated by dopaminergic mechanisms in the NAc, there is evidence that the integrity of the NAc is important in mediating the posttraining memory enhancing effects of BLA glucocorticoid receptor activation (Roozendaal et al., 2001). It is conceivable, however, that dopaminergic mechanisms (within the NAc) concerned with the acquisition of Pavlovian learning, in which different forms of limbic afferents compete for associative control over behavior, may differ from those engaged in the consolidation of those associations. Indeed, pretraining and posttraining infusions of a DA receptor agonist into the amygdala have been shown to have opposite effects (inhibitory and facilitatory effects, respectively) on Pavlovian appetitive conditioning (Phillips and Hitchcott, 2009). Furthermore, Phillips et al. (2003) found that posttraining amphetamine infusions into the NAc shell enhance conditioned responding to a discrete reward cue, which, together with evidence that concurrent DA receptor activation in the amygdalaNAc shell pathway is necessary for the modulation of fear-related memory consolidation (LaLumiere et al., 2005), implicates NAc shell DA in memory consolidation. Clearly, there is scope for further investigation into whether the same dopaminergic mechanisms in the NAc shell and core and limbic structures govern the acquisition, consolidation, and expression of HPC-dependent and amygdala-dependent memory.

\section{Opposing function of NAc core and shell DA in limbic processing}

In the present study, increased activity of DA in the NAc shell and core had opposite effects on spatial conditioning, with repeated amphetamine infusions into the NAc shell enhancing, and infusions into the NAc core progressively attenuating, spatial control over conditioned preference. Importantly, the direction of the effects was reversed with DA receptor blockade, with NAc core DA receptor antagonism enhancing spatial control over appetitive learning. These findings are highly consistent with previous reports of functionally opposing effects of NAc core and shell excitotoxic and 6-hydroxydopamine lesions on nicotine conditioned place preference and amphetamine-induced impulsive behavior, respectively (Murphy et al., 2008; Sellings et al., 2008). Sellings et al. (2008) found that NAc shell DA denervation abolished nicotine conditioned place preference, while NAc core DA denervation had the opposite effect of enhancing conditioned place preference. Moreover, Murphy et al. (2008) found that postacquisition NAc core lesions potentiated systemic amphetamine-induced premature responding in a forced choice instrumental task, in which rats were trained to respond to brief presentations of a flashing light in a single hole, while NAc shell lesions attenuated premature responding. Together, these findings implicate a potential regulatory role for NAc core DA in the control of NAc shell-mediated influences over appetitive behavior. Such a role is conceivable, given recent anatomical evidence that there are direct connections between the subregions, with inhibitory GABA fibers arising from the NAc core being more dense and projecting over a wider area of the shell than those that project from the NAc shell to the core (van Dongen et al., 2005). A recent neurophysiological study has also implicated the NAc core, but not the shell, in acting as a "relay station" in dynamically selecting the most appropriate corticolimbic input to drive accumbens activity (Gruber et al., 2009).

There is currently much consensus that information processing through corticostriatal structures occurs through a series of ascending spiraling loops, with the NAc shell and associated cortical areas occupying top position in the hierarchy (Haber et al., 2000). The identification of several multisynaptic pathways that run from the shell, via ventral pallidal-thalamic-prefrontal connections, and also via DA neurons in the ventral tegmental area and substantia nigra pars compacta, to the NAc core supports this view (see Groenewegen et al., 1999). The present data, however, provide novel evidence to suggest that functional interactions between the NAc core and shell may be more complex, and that influence can be bidirectional, with NAc core DA modulating NAc shell activity, as well as NAc shell-to-core modulation.

In conclusion, the present findings suggest that the dopaminergic innervations of the NAc shell and core have distinct, and even opposing, roles in the regulation of limbic information processing through the NAc. NAc shell DA is critical in allowing HPC inputs to gain preferential control over appetitive learning, while NAc core DA has a twofold role, not only in allowing BLA inputs to dominate in the control over appetitive learning, but also to dampen HPC-NAc shell-mediated information flow. This is highly consistent with the idea that the NAc core acts as a relay station in integrating and selecting the most relevant input among competing limbic and cortical afferents that will subsequently drive behavioral output.

\section{References}

Bossert JM, Poles GC, Wihbey KA, Koya E, Shaham Y (2007) Differential effects of blockade of dopamine $\mathrm{D}_{1}$-family receptors in nucleus accumbens core or shell on reinstatement of heroin seeking induced by contextual and discrete cues. J Neurosci 27:12655-12663.

Carr GD, White NM (1983) Conditioned place preference from intraaccumbens but not intra-caudate amphetamine injections. Life Sci 33:2551-2557.

Chaudhri N, Sahuque LL, Schairer WW, Janak PH (2010) Separable roles of the nucleus accumbens core and shell in context- and cue-induced alcohol-seeking. Neuropsychopharmacology 35:783-791.

Floresco SB, Blaha CD, Yang CR, Phillips AG (2001) Modulation of hippocampal and amygdalar-evoked activity of nucleus accumbens neurons by dopamine: cellular mechanisms of input selection. J Neurosci 21:2851-2860.

French SJ, Totterdell S (2002) Hippocampal and prefrontal cortical inputs monosynaptically converge with individual projection neurons of the nucleus accumbens. J Comp Neurol 446:151-165.

French SJ, Totterdell S (2003) Individual nucleus accumbens-projection neurons receive both basolateral amygdala and ventral subicular afferents in rats. Neuroscience 119:19-31.

Fuchs RA, Evans KA, Parker MC, See RE (2004) Differential involvement of the core and shell subregions of the nucleus accumbens in conditioned cue-induced reinstatement of cocaine seeking in rats. Psychopharmacology (Berl) 176:459-465.

Goto Y, Grace AA (2005) Dopaminergic modulation of limbic and cortical drive of nucleus accumbens in goal-directed behavior. Nat Neurosci 8:805-812.

Grace AA (2000) Gating of information flow within the limbic system and the pathophysiology of schizophrenia. Brain Res Brain Res Rev 31: $330-341$ 
Groenewegen HJ, Wright CI, Beijer AV, Voorn P (1999) Convergence and segregation of ventral striatal inputs and outputs. Ann N Y Acad Sci 877:49-63.

Gruber AJ, Hussain RJ, O'Donnell P (2009) The nucleus accumbens: a switchboard for goal-directed behaviors. PLoS ONE 4:e5062.

Haber SN, Fudge JL, McFarland NR (2000) Striatonigrostriatal pathways in primates form an ascending spiral from the shell to the dorsolateral striatum. J Neurosci 20:2369-2382.

Ito R, Canseliet M (2010) Amphetamine exposure selectively enhances hippocampus-dependent spatial learning and attenuates amygdaladependent cue learning. Neuropsychopharmacology 35:1440-1452.

Ito R, Dalley JW, Howes SR, Robbins TW, Everitt BJ (2000) Dissociation in conditioned dopamine release in the nucleus accumbens core and shell in response to cocaine cues and during cocaine-seeking behavior in rats. J Neurosci 20:7489-7495.

Ito R, Robbins TW, McNaughton BL, Everitt BJ (2006) Selective excitotoxic lesions of the hippocampus and basolateral amygdala have dissociable effects on appetitive cue and place conditioning based on path integration in a novel Y-maze procedure. Eur J Neurosci 23:3071-3080.

Ito R, Robbins TW, Pennartz CM, Everitt BJ (2008) Functional interaction between the hippocampus and nucleus accumbens shell is necessary for the acquisition of appetitive spatial context conditioning. J Neurosci 28:6950-6959.

LaLumiere RT, Nawar EM, McGaugh JL (2005) Modulation of memory consolidation by the basolateral amygdala or nucleus accumbens shell requires concurrent dopamine receptor activation in both brain regions. Learn Mem 12:296-301.

McDonald RJ, White NM (1993) A triple dissociation of memory systems: hippocampus, amygdala, and dorsal striatum. Behav Neurosci 107:3-22.

Mogenson GJ, Jones DL, Yim CY (1980) From motivation to action: functional interface between the limbic system and the motor system. Prog Neurobiol 14:69-97.

Murphy ER, Robinson ESJ, Theobald DEH, Dalley JW, Robbins TW (2008) Contrasting effects of selective lesions of nucleus accumbens core or shell on inhibitory control and amphetamine-induced impulsive behaviour. Eur J Neurosci 28:353-363.

Packard MG, Teather LA (1998) Amygdala modulation of multiple memory systems: hippocampus and caudate-putamen. Neurobiol Learn Mem 69:163-203.

Packard MG, Cahill L, McGaugh JL (1994) Amygdala modulation of hippocampal-dependent and caudate nucleus-dependent memory processes. Proc Natl Acad Sci U S A 91:8477-8481.

Paulson PE, Robinson TE (1995) Amphetamine-induced time-dependent sensitization of dopamine neurotransmission in the dorsal and ventral striatum: a microdialysis study in behaving rats. Synapse 19:56-65.

Paxinos G, Watson C (1997) The rat brain in stereotaxic coordinates, Ed 3. San Diego: Academic.

Pennartz CM, Groenewegen HJ, Lopes da Silva FH (1994) The nucleus accumbens as a complex of functionally distinct neuronal ensembles: an integration of behavioural, electrophysiological and anatomical data. Prog Neurobiol 42:719-761.
Phillips GD, Hitchcott PK (2009) Blockade of the acquisition, but not expression, of associative learning by pre-session intra-amygdala $\mathrm{R}(+)$ 7-OH-DPAT. Psychopharmacology (Berl) 203:161-173.

Phillips GD, Setzu E, Hitchcott PK (2003) Facilitation of appetitive Pavlovian conditioning by d-amphetamine in the shell, but not the core, of the nucleus accumbens. Behav Neurosci 117:675-684

Pierce RC, Kalivas PW (1995) Amphetamine produces sensitized increases in locomotion and extracellular dopamine preferentially in the nucleus accumbens shell of rats administered repeated cocaine. J Pharmacol Exp Ther 275:1019-1029.

Pierce RC, Kalivas PW (1997) A circuitry model of the expression of behavioral sensitization to amphetamine-like psychostimulants. Brain Res Brain Res Rev 25:192-216.

Pitkänen A, Pikkarainen M, Nurminen N, Ylinen A (2000) Reciprocal connections between the amygdala and the hippocampal formation, perirhinal cortex, and postrhinal cortex in rat. A review. Ann N Y Acad Sci 911:369-391.

Robinson TE, Berridge KC (1993) The neural basis of drug craving: an incentive-sensitization theory of addiction. Brain Res Brain Res Rev $18: 247-291$

Robinson TE, Berridge KC (2001) Incentive-sensitization and addiction. Addiction 96:103-114

Roozendaal B, de Quervain DJF, Ferry B, Setlow B, McGaugh JL (2001) Basolateral amygdala-nucleus accumbens interactions in mediating glucocorticoid enhancement of memory consolidation. J Neurosci 21: $2518-2525$.

Sellings LHL, Baharnouri G, McQuade LE, Clarke PBS (2008) Rewarding and aversive effects of nicotine are segregated within the nucleus accumbens. Eur J Neurosci 28:342-352.

Taylor JR, Horger BA (1999) Enhanced responding for conditioned reward produced by intra-accumbens amphetamine is potentiated after cocaine sensitization. Psychopharmacology (Berl) 142:31-40.

Taylor JR, Robbins TW (1984) Enhanced behavioral control by conditioned reinforcers following microinjections of d-amphetamine into the nucleus accumbens. Psychopharmacology (Berl) 84:405-412.

van Dongen YC, Deniau J-M, Pennartz CMA, Galis-de Graaf Y, Voorn P, Thierry A-M, Groenewegen HJ (2005) Anatomical evidence for direct connections between the shell and core subregions of the rat nucleus accumbens. Neuroscience 136:1049-1071.

Voorn P, Vanderschuren LJMJ, Groenewegen HJ, Robbins TW, Pennartz CMA (2004) Putting a spin on the dorsal-ventral divide of the striatum. Trends Neurosci 27:468-474.

Wyvell CL, Berridge KC (2000) Intra-accumbens amphetamine increases the conditioned incentive salience of sucrose reward: enhancement of reward "wanting" without enhanced "liking" or response reinforcement. J Neurosci 20:8122-8130.

Zahm DS (1999) Functional-anatomical implications of the nucleus accumbens core and shell subterritories. Ann N Y Acad Sci 877:113-128.

Zahm DS (2000) An integrative neuroanatomical perspective on some subcortical substrates of adaptive responding with emphasis on the nucleus accumbens. Neurosci Biobehav Rev 24:85-105. 